\title{
BERGER, PETER L. THE MANY ALTARS OF MODERNITY: TOWARD A PARADIGM FOR RELIGION IN A PLURALIST AGE. BOSTON/BERLIN: WALTER DE GRUYTER, 2014, 147 P.
}

Renan B. Dantas ${ }^{1}$

A contribuição teórica para a sociologia da religião feita por Peter L. Berger dispensa comentários. Na década de 60 em "O Dossel Sagrado" (1967), Berger defendeu sua teoria da secularização ${ }^{2}$, cujo argumento central é o de que a modernidade estruturalmente afasta a religião do controle e dominação de setores sociais e culturais (como o Estado e a educação) e individualmente faz com que ela (religiáo) deixe de ser plausível. Isso implicava entender, como muitos outros sociólogos da religiáo de seu tempo, que no mundo moderno a religiáo náo teria um futuro "promissor".

Porém, com o passar dos anos - também junto de muitos outros sociólogos da religião ${ }^{3}$ - Berger passa a abandonar algumas de suas opinióes anteriores sobre a secularização. $\mathrm{O}$ autor passou a confrontar a ideia central da teoria - segundo a qual, a religiáo na modernidade exponencialmente deixa de exercer domínio sobre instituiçóes e consciências - com evidências

1 Bacharelando em Antropologia pela Universidade Estadual de Campinas (UNICAMP). Contato: renan_dantas28@hotmail.com

2 Interessante pontuar que aqui Berger seguia os passos de alguém que foi "treinado pela tradição sociológica moldada por Max Weber” (BERGER, 1997b, p. 15), observando a religião sob uma posição autônoma entre variáveis independentes, ou seja, reconhecendo-lhe "autonomia e capacidade de exercer um papel autônomo nos processos sociais, mesmo se estes, por sua vez, possam influenciá-la” (MARTELLI, 1995, p. 74).

3 Berger comenta que um dos poucos autores a se manterem defendendo a secularizaçáo foi o britânico Steve Bruce. Berger relata que em 2001, este autor "suggested that I should recant my "unnecessary recantation" of secularization theory and, as it were, return to the fold. I did not accept the suggestion then, and I am not about to accept it now" (Berger, 2014, p. XII). 
empíricas no cenário global ${ }^{4}$, que o levavam a um outro diagnóstico o de que os processos de modernização e secularização não estão necessariamente ligados numa relação de causa e efeito. Esta relação se daria somente em alguns casos específicos, mais precisamente em duas subculturas modernas: numa cultura euro-secular - alguns países europeus onde a religiáo institucionalmente declinou - e numa certa elite internacional globalizada, marcada por educação superior. Fora isso, na década de 90 Berger vai identificar um "ressurgir" da religião, uma "dessecularização do mundo" (1999), no meio de um contexto onde:

"algumas instituições religiosas perderam poder e influencia em muitas sociedades, mas crenças e práticas religiosas antigas ou novas permaneceram na vida das pessoas, às vezes assumindo novas formas institucionais e às vezes levando a grandes explosões de fervor religioso. Inversamente, instituições religiosamente identificadas podem desempenhar um papel social ou politico mesmo quando muito poucas pessoas confessam ou praticam a religiáo que essas instituiçóes representam" (Berger, 2001, p. 10).

Agora, mais recentemente em “The Many Altars of Modernity” (2014), o sociólogo austro-americano revê mais uma vez seu pensamento perante a situação da religião na modernidade, se dispondo a contribuir para a produção de um novo paradigma de entendimento desta relação. Segundo Berger, o pluralismo religioso foi interpretado de maneira errada. Este fenômeno seria a maior mudança que a modernidade trouxe para a religiáo, tanto nas

4 Principalmente no florescimento das forças islâmicas e evangélicas. Apesar de distintos, no que se refere a conteúdo religioso e presença no mundo, segundo Berger estes dois movimentos seriam os mais dinâmicos, apresentando como ponto em comum a proposta de reelaboração da identidade individual e coletiva, ofertando como promessa a tão almejada segurança e certeza existencial-cognitiva. Segundo o autor, tais grupos podem ser entendidos como fundamentalistas, termo que apesar de "pejorativo" é sugestivo de "uma combinação de várias características, como forte paixão religiosa, um desafio ao que foi tido como o Zeitgeist, e uma volta às fontes tradicionais de autoridade religiosa" (Berger, 2001, p. 13).

Debates do NER, Porto Alegre, ano i 8, N. 3 I, P. 343-353, JAN./Jun. 20 I 7 
mentes individuais quanto para ordem institucional. E, ele pode ou não estar associado à secularização, mas é independente dela.

Logo no prefácio, Berger resume o argumento central de seu livro, que lhe teria ocorrido de maneira "inesperada" no ano de 2012. A diferenciação, entendida por ele anteriormente como secularização objetiva, na qual o individuo "é assediado por uma vasta gama de tentativas de definição da realidade, religiosas ou não, que competem por obter sua adesão ou, pelo menos, sua atenção" (Berger, 1985, p. 139) - ou seja, por diferentes instituiçóes - teria correspondência na mente dos indivíduos, que operam cognitivamente em diferentes espécies de discursos. Está é sua principal contribuição neste livro, a de que o pluralismo religioso sócio-estrutural tem espaço correlato também nas consciências individuais, onde se interpenetram discursos tanto religiosos quanto seculares.

De tal forma, a pluralização e a diferenciação não conduziriam ao declínio da religiáo (como suposto no passado), mas sim a um realinhamento do papel da religião nas vidas individuais. E neste contexto:

"Most religious people, even very fervent ones, operate within a secular discourse in important áreas of their lives. Put differently, for most believers there is not a stark either/or dichotomy between faith and secularity but rather a fluid construction of both/and" (Berger, 2014, p. X).

A partir daí então Berger passa a elaborar um ensaio sobre esta importante idéia, em uma obra composta por seis capítulos escritos por ele, nos quais discorre sobre a relação da religião com a modernidade que "necessarily leads to pluralism" (Berger, 2014, p. 20), em diferentes níveis: individual, institucional, político, global, etc. E há ainda, três capítulos escritos por renomados sociólogos da religião (Nancy Ammerman, Detlef Pollack e Fenggang Yang) em resposta ao novo trabalho de Berger.

Disposto a descrever o fenômeno pluralista enquanto um fato empírico na sociedade, experimentado por pessoas comuns, Berger então o define como "a social situation in which people with differente ethnicities, worldviews and moralities live together peacefully andinteract with each other 
amicably" (Berger, 2014, p. 1). Essa interação entre pontos de vista diferentes se deflagraria em um processo denominado pelo autor como "contaminação cognitiva”. Diante dela, ele elenca duas proposiçóes: a primeira seria a de que a contaminação cognitiva relativiza as visóes de mundo e sistemas de valores e a segunda que o pluralismo produz uma contaminação cognitiva como condição continua. Conjugadas, as duas proposições trazem a tona uma situação na qual a relativização se torna uma experiência permanente na sociedade moderna.

Neste sentido, o fenômeno também estaria associado ao processo de modernização da sociedade ocidental, que desde a revolução industrial, tem transformado a condição humana no que se refere a seu destino e suas escolhas. Sustentado pelo sistema capitalista, esse processo aumentou a exponencialidade da escolha, congregando tudo em um enorme mercado(s) de serviços e produtos que náo deixa a religião de lado.

Nesta situação as certezas dos indivíduos são relativizadas e minadas, tornando-se cada vez mais incomodas. Para Berger, isso explica porque "so many modern people are anxious, and incidentally why the calm certainty of pre-modern societies is attractive and becomes a utopia for a lot of nervous moderns" (Berger, 2014, p. 9). Diante dessa ansiedade existencial, o autor identifica no mundo contemporâneo, duas saídas extremas: fundamentalismo e relativismo. A primeira consistiria num esforço para restaurar a certeza ameaçada, que pode ser religiosa ou secular (política, filosófica, estética, culinária), já que praticamente qualquer idéia (reacionária ou progressiva) ou prática pode se tornar a base de um projeto fundamentalista. E neste ponto, Berger diferencia o fundamentalismo baseado em uma tradição ou em um neo-tradicionalismo, sendo que o segundo difere do primeiro à medida que a tradição vivenciada é fruto de uma escolha, diferente do contexto pré-moderno onde não havia espaço para a dúvida.

A isso estaria ligado um dos principais efeitos do pluralismo segundo Berger, o de alterar o "como" da fé individual, ao invés do "quê". Para ilustrá-lo o autor cita o caso que tem sido denominado "fenômeno da terceira geração", que se refere a netos que passam a adotar as crenças de seus avós, 
que haviam sido rejeitadas pelos seus pais. Entre o avô e o neto, o "quê" da fé de ambos (ou seja, seu conteúdo) continua o mesmo, porém no que se refere ao "como", o que anteriormente era um destino dado como certo, agora se tornou uma escolha deliberada.

Por sua vez, o relativismo seria o aceite da relatividade que apavora os fundamentalistas, na qual, o individuo não tem certeza de nada, pois a seu ver não há nenhuma verdade absoluta, cognitiva ou normativa. Assim, diante dessas "chaves" à "proliferação dos altares", Berger argumenta que:

"Both fundamentalism and relativism make the problem intractable. Fundamentalism balkanizes a society, leading either to ongoing conflict or to totalitarian coercion. Relativism undermines the moral consensus without which no society can survive. The political problem of pluralism can only be solved by the maintenance and legitimation of the middle ground between these two extremes" (Berger, 2014, p. 15)

Berger também se propóe a discutir a relação do pluralismo com as instituiçóes religiosas. Aqui o autor recorre ao trabalho do alemão Arnold Gehlen, que disserta sobre o processo de desinstitucionalização ${ }^{5}$ da sociedade moderna, correspondente a subjetivação do comportamento internalizado dos indivíduos, que passam agora cada vez mais a contar com a própria consciência para decidir seu modo de agir.

Para tanto, o autor enfatiza que para entender o efeito do pluralismo sobre a religião, é necessário distinguir os níveis: individual e coletivo. Se no primeiro ele permite que os indivíduos sejam agentes do seu próprio

5 O inverso deste processo - o de institucionalização - é discutido por Berger em em sua "sociologia do conhecimento", cuja obra clássica trata-se de "A Construção Social da Realidade" (1966), escrita em parceria com Thomas Luckmann. Nela o sociólogo vai afirmar que "a institucionalização ocorre sempre que há uma tipificação recíproca de açôes habituais por tipos de atores. Dito de maneira diferente, qualquer uma dessas tipificaçóes é uma instituição [...] pelo simples fato de existirem (as instituiçóes), controlam a conduta humana estabelecendo padróes previamente definidos de conduta, que canalizam em uma direção por oposição à muitas outras direções que seriam teoricamente possíveis" (Berger, 1997a, p. 79-80). 
destino, no segundo ele gera como correlato da escolha individual a associação voluntária, a forma social típica da situação pluralista. Portanto, o pluralismo ao elencar o voluntarismo como forma predominante, não só altera o caráter das instituiçôes religiosas, mas também muda as relaçôes dos indivíduos com as demais instituiçôes sociais. Isto estaria ligado ao processo mais amplo já citado por Berger, da "diferenciação institucional", desencadeado em última instância pela complexificação da divisão do trabalho nas sociedades modernas.

Nesta situação as instituições religiosas se deparam com um problema específico, o da dificuldade em lidar "with religious freedom, especially they claim to possess divinely revealed truths, and even more so if they once held a monopoly position in a society" (Berger, 2014, p. 38). Assim, a liberdade religiosa acaba por privar as instituiçóes dos privilégios de monopólio anteriores, forçando-as a competir entre si sem recorrer à coerção. Pressóes em direção ao controle desta concorrência são feitas, e segundo Berger, esforços voltados a respondê-las são traduzidos na forma do ecumenismo ${ }^{6}$ por exemplo.

Retomando o argumento de que a tese da secularização se equivocou ao supor que a modernidade conduz ao declínio da religiáo, ele identifica que a modernidade produz sim um discurso secular, que abdica de qualquer noção de transcendência para se desenvolver e que se torna referencia para diferentes áreas da vida moderna. A partir daí seu percurso segue a pista de que se há um pluralismo de opçôes religiosas coexistindo na sociedade, há também o seu correlato nas consciências dos indivíduos através da diferenciação das áreas: religiosa e secular.

Berger vai dizer que a análise do surgimento desse discurso secular, que nasce da diferenciação das áreas, passa por Karl Jasper que tratou sobre

6 O ecumenismo foi um assunto já abordado por Berger em o "Dossel Sagrado" (1967), entendido como conseqüência da "secularização objetiva", "no sentido de uma colaboração amigável cada vez mais estreita entre os diferentes grupos envolvidos no mercado religioso [...] exigido pela situação pluralista como um todo" (Berger, 1985, p. 153). 
a "idade axial" ", Eric Voegelin que descreveu as mudanças da visão mitológica à racional em um movimento de "'compactness (reality experienced as one unified whole) to 'differentiation' (opening up a gap between transcendence and immanence)" (Berger, 2014, p. 51) e por Max Weber, que estava focado na mentalidade racional moderna que originou a ciência e a tecnologia.

As características deste discurso estariam imbricadas a modernidade e a ciência, que necessariamente, segundo Berger, operam predominantemente em um discurso secular, estritamente imanente, "como se Deus não existisse" ${ }^{8}$. Pela racionalidade do discurso ter prolongado a vida humana e dominar instituiçóes como a da medicina moderna, ele teria como aponta o autor um prestígio maior na sociedade atual ${ }^{9}$. Isso porém, não implica dizer que para os indivíduos ambos os tipos de discursos são exclusivos, na verdade "in the experience of most individuals, secularity and religion are not mutually contradictory" (Berger, 2014, p. 53).

Assim, na prática os dois discursos se misturam, o individuo tem suas crenças, mas também suas dúvidas, inclusive referente às primeiras. Para compreender este caso, Berger recorre a Alfred Schutz, que enxerga a consciência a partir do conceito de "realidades múltiplas", no qual a mente humana

7 "A period somewhere between the eighth and fifth centuries BCE, when in all major civilizations decisive changes of worldview took place” (Berger, 2014, p. 51).

8 Frase de Hugo Grotius, jurista holandês do século XVII, que propôs uma disciplina para o Direito Internacional na qual "etsi Deus non daretur", "como se Deus não existisse". "In other words, he proposed that an entire institution should be divorced from any religious presuppositions and should be dominated by a strictly secular discourse" (Berger, 2014, p. X).

9 Detlef Pollack em sua resposta ao ensaio de Berger problematiza este argumento. Segundo ele, se a comunicação secular se torna um discurso privilegiado, automaticamente atribui-se aos discursos religiosos um status de uma linguagem secundária, que estará sob constante pressão de justificação. Assim "is not discernible how such a secondary language competing with the primary one can reach persistency and co-existence with the primary code without being challenged, and someday perhaps even overpowered, by the latter" (Pollack, 2014, p. 119). 
se divide basicamente entre a "realidade cotidiana", aquela compartilhada com os demais indivíduos, e a "realidade finita", a consciência mais pessoal, abordada por Berger nos termos de "virtuosi" (Weber), uma experiência religiosa mais intensa, e a experiência do "totalmente outro" de Rudolf Otto. Como exemplo, Berger cita o caso dos místicos, como Teresa D’ávila, que tinha grandes êxtases mas que eram temporários, na "realidade cotidiana" até mesmo ela tinha de lidar com a gerência da economia de seu convento por exemplo.

$\mathrm{Na}$ mediação entre os discursos que acontece na mente dos indivíduos, Berger salienta que há um impulso para a coerência, mas que por vezes é tênue ou vaga, como por exemplo, no caso de um católico reencarnacionista. Porém ele explica que "Since pluralism means that individuals put together their religious beliefs like a child uses Lego pieces to construct an idiosyncratic edifice, it is not surprising that some of the ensuing constructions look a bit Odd" (Berger, 2014, p. 57).

Outro ponto importante do livro é a aplicação empreitada por Berger do conceito de "modernidades múltiplas", proposto pelo sociólogo israelense Samuel Eisenstadt, a religião contemporânea. Essa noção substitui a visão predominante desde o iluminismo, de que havia apenas uma versão da modernidade, a engendrada pela civilização ocidental, pela idéia de que encontramos ao longo da história diferentes versôes da modernidade, onde inclusive a religião tem um papel mais central. Como exemplo, Berger cita o caso do Japão que em seu processo de modernização, a Restauração Meiji, manteve muitos traços de sua cultura pré-moderna, inclusive seus componentes religiosos do budismo (e sua variedade de escolas), do xintoísmo e da ética confucionista.

Berger, portanto, deixa claro que a multiplicidade de versóes da modernidade estaria ligada à pluralidade de estruturas de relevância ${ }^{10}$ (da tecnologia,

${ }^{10}$ Esta é uma idéia fundamental para obra de Berger, retirada de sua sociologia do conhecimento, tratada em seus trabalhos anteriores sob a noção de plausibilidade. Em "Rumor de Anjos" (1969) ele diz que "uma das proposições fundamentais da sociologia do

Debates do NER, Porto Alegre, ano i 8, N. 3 I, P. 343-353, Jan./Jun. 20 I 7 
da burocracia, do capitalismo e da religião em suas diferentes formas), que se influenciam e interpenetram, como no caso de fiéis que olham suas religiôes a partir do prisma da medicina cientifica e no de organizaçóes religiosas que são invadidas por uma ordem burocrática. Segundo o autor, este é um ponto que nos permite entender que a tese da secularização não estava de todo errada. Nota-se um discurso secular que se desenvolve e se difunde, mas que, porém não substitui o discurso religioso, nem mesmo em casos de uso de coerção violenta por parte da sociedade política (como aconteceu, por exemplo, em alguns estados comunistas).

Berger ressalta que, uma vez estabelecido o discurso secular, tanto nas mentes como na sociedade de maneira geral, os conflitos e as negociaçóes de fronteira se tornam inevitáveis, a ponto de encontrarmos de um lado ateus que anseiam explicar todos fenômenos religiosos a partir da neurologia e de outro tentativas de retratar a religiáo como ciência (como por exemplo na "ciência cristâ" de Mary Baker Eddy e na Antroposofia de Rudolf Steiner), colapsando neste último caso as fronteiras entre o religioso e o secular.

Sintetizando o que foi dito até aqui, Berger argumenta que:

"There is a pluralism of religious discourses in the minds of individuals and in society. There is also the centrally important pluralism between secular and religious discourses. Also, there is a pluralism of different versions of modernity, with different delineations of the co-existence of religion and secularity. Pluralism must be politically managed" (Berger, 2014, p. 78).

Sobre o ultimo elemento da citação (a administração política do pluralismo) o autor vai dizer que uma teoria do fenômeno que seja útil, necessariamente deve combinar seu aspecto individual com o político,

conhecimento é que a plausibilidade, no sentido daquilo que as pessoas realmente acham digno de fé, das idéias sobre a realidade depende de suporte social que estas idéias recebem" (Berger, 1997, p. 65). Ou seja, elas são estruturas coletivas de percepção da sociedade enquanto realidade objetiva, que favorecem ao ser humano um mundo existencialmente habitavel.

Debates do NER, Porto Alegre, Ano i 8, N. 3 I, P. 343-353, JAn./JUn. 20 I 7 
na medida em que na situação pluralista se produz dois problemas políticos distintos: o primeiro que se refere à forma como ele define sua relação com a religião e segundo como ele se propóe a regular a relação entre as diferentes religióes. Na prática, isso nos conduziria a busca de "fórmulas de paz", maneiras de assegurar a coexistência de diferentes tradiçôes religiosas em uma mesma sociedade. Berger analisa cinco grandes fórmulas que diferentes sociedades usaram para lidar com problemas como esse ao longo da história e argumenta que em um contexto de neutralidade estatal - ou seja, de separação da "Igreja e do Estado" - a liberdade religiosa é, de longe, a melhor de todas.

De maneira geral, a obra colabora bastante com sociologia da religião ao abordar questóes chaves para a relação religião modernidade, tornando mais claro o fenômeno atual da coexistência de muitos sistemas religiosos e morais num mesmo espaço social, que irrevogavelmente alteram a natureza da religiâo. Também esclarece pontos um pouco "nebulosos" dos trabalhos mais recentes do autor. Com certeza é uma obra bastante importante, que aguarda tradução para língua portuguesa. 


\section{REFERÊNCIAS}

BERGER, Peter L. O dossel sagrado: elementos para uma teoria sociológica da religião. São Paulo: Ed. Paulinas, 1985.

BERGER, Peter L.; LUCKMANN, Thomas. Construção social da realidade. Petrópolis: Vozes, 1997a.

. Rumor de anjos: a sociedade moderna e a redescoberta do sobrenatural. Petrópolis: Vozes, 1997b.

. A dessecularização do mundo: uma visão global. Religião e sociedade, v. 21, n. 1, p. 9-24, 2001.

. The many altars of modernity: Toward a paradigm for religion in a pluralist age. Berlin: Walter de Gruyter, 2014.

MARTELLI, Stefano; BALANCIN, Euclides Martins. A religiāo na sociedade pós-moderna: entre secularização e dessecularização. São Paulo: Paulinas, 1995.

Recebido em: 12/12/2016 Aprovado em: 20/12/2016 
